\title{
Notes from the Editor
}

\section{ANNOUNCEMENT}

The inaugural issue of the American Political Science Review was published in November of 1906. To mark the centennial of the APSR, the November 2006 issue will feature a special section devoted to considerations of the evolution of political science. This special section will be an extra feature, above and beyond the regular complement of research articles.

The APSR is actively soliciting submissions on the broad theme of the special section.

If you are interested in submitting a paper, please contact the editor of the APSR at apsr@gwu.edu to express your interest and to provide a brief description of the paper you would like to submit. Also, please bring this solicitation to the attention of others who may be interested and encourage them to contact the editor.

Like all other papers submitted to the APSR, submissions received in response to this solicitation will undergo peer review. Overseeing this process will be the editor of the APSR, Lee Sigelman, and a member of the APSR's editorial board, M. Elizabeth Sanders of Cornell University.

To be considered for publication, a paper must be no more than 15-17 pages in length, conventionally formatted (e.g., double-spaced throughout, including notes and references, with margins of at least one inch on all sides and set up in at least an 11-point font size).

In light of the length constraints, authors are advised to address a specific theme rather than aiming at a broader, synoptic disciplinary overview. Pertinent examples would include: an analysis of a particular turning point in the evolution of the discipline or of the role played by a particular individual; a treatment of the evolution of some influential school of thought; a comparison of the evolution of two subfields of political science, or of political science in the U.S. and another area, or of political science and another discipline; or a consideration of how a certain type of scholarship has influenced and/or been influenced by public policy, or the relationship between political science and the state. (These are offered only as examples, rather than as a definitive set of topics to be addressed.)

To be considered for publication, submissions must reach the APSR office by no later than January 2,2006 , but earlier submission is encouraged.

\section{Inside this Issue}

Relationships ranging from the interpersonal to the international are built on trust. A prerequisite for friendship and cooperation, trust involves a sense of reliance on or confidence in another, especially when one is vulnerable. Trust is built up over time by repeated confirming instances of support, but it can erode over time due to disappointing interactions, and it can even be erased completely in a single act of treachery. Our cover picture of trapeze artists in midair points to the amazing feats that can be accomplished when trust is earned and maintained, yet it also hints at the devastating consequences that can arise when trust is misplaced. These themes run through the articles in this issue of APSR.

From smirks and sighs during presidential debates to hard-hitting attack ads, campaigning for political office, always a contact sport, has increasingly been plagued by "unnecessary roughness" in recent years. In "The New Videomalaise: Effects of Televised Incivility on Political Trust," Diana C. Mutz and Byron Reeves examine the impact of disparaging political discourse. Mutz and Reeves build on an extensive body of scholarship that has assumed or hypothesized, but has yet to convincingly demonstrate, a direct relationship between viewing televised campaign coverage and holding "negative" political attitudes. Based on an innovative research design that involves, among other elements, a mock congressional campaign debate performed by professional actors and readouts from skin conductance electrodes, Mutz and Reeves establish a direct link between specific types of televised political discourse and levels of political trust. These findings yield surprising insights about the malleability of political trust and suggest anew that in politics, what you say may be less important than how you say it.

The potential undermining of trust during an election cycle is not necessarily limited to the campaign. According to Mark Andreas Kayser, the costs of an election extend far beyond what a tally sheet of campaign expenditures and operating costs might suggest. In "Who Surfs, Who Manipulates? The Determinants of Opportunistic Election Timing and Electorally Motivated Economic Intervention," Kayser explores the relationship between elections and politically motivated economic intervention. Governments with the ability to call elections within a broad time period, he suggests, are less likely to manipulate the economy for electoral purposes. Assuming that politically motivated economic interventions constitute an inefficient use of budgetary resources, their elimination would lower the incidental costs of elections. This analysis is a mustread, especially for those in fixed-election democracies. 
Of course, playing fast and loose with the rules is not confined to domestic politics. In an era of increasing globalization, states are no longer the only actors that need to be held accountable. In "Accountability and the Abuse of Power in World Politics," Ruth W. Grant and Robert O. Keohane go beyond the simple assertion that the accountability processes at work within democratic states can be transferred to the international system. Instead, they offer a typology of accountability mechanisms for different international actors, including states, as well as intergovernmental institutions, transnational networks, and nongovernmental organizations. This typology not only advances prior theoretical and conceptual understandings of accountability in its international context, but also provides both a checklist for scrutinizing international actors and a road map for international actors that are attentive to accountability concerns.

Responsible global politics requires not only mechanisms of accountability, but something of a common identity, or at least a modicum of trust between international actors. Continuing in the same line of scholarship that was evidenced in his September 2002 APSR article, "Does Liberal Democracy Presuppose a Cultural Nation? Four Arguments," Arash Abizadeh questions the widely held supposition that in-group solidarity requires the presence of an out-group against which to frame group identity. Such a belief would make it impossible to create an all-encompassing global identity, which would, by definition, lack the requisite outgroup. However, Abizadeh argues, in "Does Collective Identity Presuppose an Other? On the Alleged Incoherence of Global Solidarity," that this conception of identity is fundamentally flawed. Although many obstacles to the creation of a global identity remain, Abizadeh removes one significant point of misunderstanding from its path.

The politics of us-versus-them is also relevant to answering questions regarding domestic politics. For example, why do we often see social democratic parties acting in opposition to their own self-interests? In "Insider-Outsider Politics in Industrialized Democracies: The Challenge to Social Democratic Parties," David Rueda argues that that is the wrong question because it starts from an incorrect premise. Social democratic parties are not cohesive advocates of labor but, instead, are composed of both labor "insiders" and "outsiders." This heterogeneity results in divergent preferences. By disaggregating social democratic parties into their constituent units, Rueda sets the stage for a new generation of research on this important topic.

Insiders and outsiders are similarly found in American politics and history. In their provocative article, "Racial Orders in American Political Development," Desmond S. King and Rogers M. Smith contend that a framework of racial orders is a critical component of any study of American politics, even for topics that are not prima facie race-related. From institutional organization to policy preferences, analyses that fail to take race seriously are lacking an important explanatory variable. At a bare minimum, scholars must justify the exclusion of race from their study, although King and
Smith advocate a more thorough treatment of the issue and urge practitioners to shine a spotlight on this issue.

With so much scholarly attention devoted to the executive or cabinet in a parliamentary government, one might be forgiven for forgetting that a parliament is first and foremost a legislative body. Lanny W. Martin and Georg Vanberg remind us of this fact in "Coalition Policymaking and Legislative Review." Going beyond the traditional focus on government formation and dissolution, Martin and Vanberg examine the tools available to governing parties, emphasizing the pivotal role of legislative review in coalition governments. Their thorough theoretical and empirical analysis demonstrates that legislators have a meaningful role to play in the policymaking process.

The next article in this issue also investigates who has meaningful decision-making roles, this time from a foreign policy perspective. Why did the United States invade Iraq? Why does the United States support Israel? Identifying the sources of influence on such weighty decisions is the focus of Lawrence R. Jacobs and Benjamin I. Page's "Who Influences U.S. Foreign Policy?" Previous research has identified organized groups, epistemic communities, and public opinion as leading domestic influences on foreign policy. Jacobs and Page present an innovative comparative test of these three sources across different issue areas and institutional settings. Their findings, which dispute commonly held beliefs among foreign policy analysts, suggest a major rethinking of American foreign policymaking.

Important decisions are made not only by superpowers with mighty armies, but also by individual citizens with meager assets. One perennial decision-making question is whether welfare recipients shop around for the most generous states in which to live. Political scientists have reached conflicting conclusions in trying to answer this important public policy question. No state wants to be known as a welfare magnet, with the attendant spiral of increasing demand and decreasing revenues, nor do most states want to be exceedingly callous toward the less fortunate, so the answer to this question has significant implications for policy makers. Michael A. Bailey assesses past research and provides new insights in "Welfare and the Multifaceted Decision to Move." Augmenting previous modeling of the welfare migration question with a more realistic and complete explanation of the considerations involved in moving across state lines, Bailey not only finds a modest but significant relationship between benefit levels and residency decisions, but also discovers that when people decide to move, there is truly no place like home.

Finally, we revisit Ethan Putterman's August 2003 APSR article, "Rousseau on Agenda-Setting and Majority Rule." Controversial in death as he was in life, Rousseau has inspired generations of scholarship and debate. Two political theorists of more recent vintage continue the discussion in our "Forum" section. First, John T. Scott contends that Putterman has misinterpreted Rousseau's argument about representation and leadership. That is an important charge in itself, but more is at stake here than the correct interpretation of Rousseau's text, for this question brings into play 
greater issues concerning both the essence and the integrity of the democratic process. Putterman's forceful response to Scott should leave readers assured that this debate is far from over.

\section{INSTRUCTIONS TO CONTRIBUTORS}

\section{General Considerations}

The APSR strives to publish scholarly research of exceptional merit, focusing on important issues and demonstrating the highest standards of excellence in conceptualization, exposition, methodology, and craftsmanship. Because the APSR reaches a diverse audience of scholars and practitioners, authors must demonstrate how their analysis illuminates a significant research problem, or answers an important research question, of general interest in political science. For the same reason, authors must strive for a presentation that will be understandable to as many scholars as possible, consistent with the nature of their material.

The APSR publishes original work. Therefore, authors should not submit articles containing tables, figures, or substantial amounts of text that have already been published or are forthcoming in other places, or that have been included in other manuscripts submitted for review to book publishers or periodicals (including on-line journals). In many such cases, subsequent publication of this material would violate the copyright of the other publisher. The APSR also does not consider papers that are currently under review by other journals or duplicate or overlap with parts of larger manuscripts that have been submitted to other publishers (including publishers of both books and periodicals). Submission of manuscripts substantially similar to those submitted or published elsewhere, or as part of a book or other larger work, is also strongly discouraged. If you have any questions about whether these policies apply in your particular case, you should discuss any such publications related to a submission in a cover letter to the Editor. You should also notify the Editor of any related submissions to other publishers, whether for book or periodical publication, that occur while a manuscript is under review by the APSR and which would fall within the scope of this policy. The Editor may request copies of related publications.

If your manuscript contains quantitative evidence and analysis, you should describe your procedures in sufficient detail to permit reviewers to understand and evaluate what has been done and, in the event that the article is accepted for publication, to permit other scholars to carry out similar analyses on other data sets. For example, for surveys, at the least, sampling procedures, response rates, and question wordings should be given; you should calculate response rates according to one of the standard formulas given by the American Association for Public Opinion Research, Standard Definitions: Final Dispositions of Case Codes and Outcome Rates for Surveys (Ann Arbor, MI: AAPOR, 2000). This document is available on the Internet at $<$ http://www.aapor.org/default.asp? page $=$ survey_methods/standards_and_best_practices/ standard_definitions $>$. For experiments, provide full descriptions of experimental protocols, methods of subject recruitment and selection, subject payments and debriefing procedures, and so on. Articles should be self-contained, so you should not simply refer readers to other publications for descriptions of these basic research procedures.

Please indicate variables included in statistical analyses by capitalizing the first letter in the variable name and italicizing the entire variable name the first time each is mentioned in the text. You should also use the same names for variables in text and tables and, wherever possible, should avoid the use of acronyms and computer abbreviations when discussing variables in the text. All variables appearing in tables should have been mentioned in the text and the reason for their inclusion discussed.

As part of the review process, you may be asked to submit additional documentation if procedures are not sufficiently clear; the review process works most efficiently if such information is given in the initial submission. If you advise readers that additional information is available, you should submit printed copies of that information with the manuscript. If the amount of this supplementary information is extensive, please inquire about alternate procedures.

The APSR uses a double-blind review process. You should follow the guidelines for preparing anonymous copies in the Specific Procedures section below.

Manuscripts that are largely or entirely critiques or commentaries on previously published APSR articles will be reviewed using the same general procedures as for other manuscripts, with one exception. In addition to the usual number of reviewers, such manuscripts will also be sent to the scholar(s) whose work is being criticized, in the same anonymous form that they are sent to reviewers. Comments from the original author(s) to the Editor will be invited as a supplement to the advice of reviewers. This notice to the original author(s) is intended (1) to encourage review of the details of analyses or research procedures that might escape the notice of disinterested reviewers; (2) to enable prompt publication of critiques by supplying criticized authors with early notice of their existence and, therefore, more adequate time to reply; and (3) as a courtesy to criticized authors. If you submit such a manuscript, you should therefore send as many additional copies of their manuscripts as will be required for this purpose.

Manuscripts being submitted for publication should be sent to Lee Sigelman, Editor, American Political Science Review, Department of Political Science, The George Washington University, Washington, DC 20052. Correspondence concerning manuscripts under review may be sent to the same address or e-mailed to apsr@gwu.edu.

\section{Manuscript Formatting}

Manuscripts should not be longer than 45 pages including text, all tables and figures, notes, references, 
and appendices. This page size guideline is based on the U.S. standard $8.5 \times 11$-inch paper; if you are submitting a manuscript printed on longer paper, you must adjust accordingly. The font size must be at least 11 points for all parts of the paper, including notes and references. The entire paper, including notes and references, must be double-spaced, with the sole exception of tables for which double-spacing would require a second page otherwise not needed. All pages should be numbered in one sequence, and text should be formatted using a normal single column no wider than 6.5 inches, as is typical for manuscripts (rather than the double-column format of the published version of the APSR), and printed on one side of the page only. Include an abstract of no more than 150 words. The APSR style of embedded citations should be used, and there must be a separate list of references at the end of the manuscript. Do not use notes for simple citations. These specifications are designed to make it easier for reviewers to read and evaluate papers. Papers not adhering to these guidelines are subject to being rejected without review.

For submission and review purposes, you may place footnotes at the bottom of the pages instead of using endnotes, and you may locate tables and figures (on separate pages and only one to a page) approximately where they fall in the text. However, manuscripts accepted for publication must be submitted with endnotes, and with tables and figures on separate pages at the back of the manuscript with standard indications of text placement, e.g., [Table 3 about here]. In deciding how to format your initial submission, please consider the necessity of making these changes if your paper is accepted. If your paper is accepted for publication, you will also be required to submit camera-ready copy of graphs or other types of figures. Instructions will be provided.

For specific formatting style of citations and references, please refer to articles in the most recent issue of the APSR. For unusual style or formatting issues, you should consult the latest edition of The Chicago Manual of Style. For review purposes, citations and references need not be in specific APSR format, although some generally accepted format should be used, and all citation and reference information should be provided.

\section{Specific Procedures}

Please follow these specific procedures for submission:

1. You are invited to submit a list of scholars who would be appropriate reviewers of your manuscript. The Editor will refer to this list in selecting reviewers, though there obviously can be no guarantee that those you suggest will actually be chosen. Do not list anyone who has already commented on your paper or an earlier version of it, or any of your current or recent collaborators, institutional colleagues, mentors, students, or close friends.
2. Submit five copies of manuscripts and a diskette containing a pdf file of the anonymous version of the manuscript. If you cannot save the manuscript as a pdf, just send in the diskette with the word-processed version. Please ensure that the paper and diskette versions you submit are identical; the diskette version should be of the anonymous copy (see below). Please review all pages of all copies to make sure that all copies contain all tables, figures, appendices, and bibliography mentioned in the manuscript and that all pages are legible. Label the diskette clearly with the (first) author's name and the title of the manuscript (in abridged form if need be), and identify the word processing program and operating system.

3. To comply with the APSR's procedure of double-blind peer reviews, only one of the five copies submitted should be fully identified as to authorship and four should be in anonymous format.

4. For anonymous copies, if it is important to the development of the paper that your previous publications be cited, please do this in a way that does not make the authorship of the submitted paper obvious. This is usually most easily accomplished by referring to yourself in the third person and including normal references to the work cited in the list of references. In no circumstances should your prior publications be included in the bibliography in their normal alphabetical location but with your name deleted. Assuming that text references to your previous work are in the third person, you should include full citations as usual in the bibliography. Please discuss the use of other procedures to render manuscripts anonymous with the Editor prior to submission. You should not thank colleagues in notes or elsewhere in the body of the paper or mention institution names, web page addresses, or other potentially identifying information. All acknowledgments must appear on the title page of the identified copy only. Manuscripts that are judged not anonymous will not be reviewed.

5. The first page of the four anonymous copies should contain only the title and an abstract of no more than 150 words. The first page of the identified copy should contain (a) the name, academic rank, institutional affiliation, and contact information (mailing address, telephone, fax, e-mail address) for all authors; (b) in the case of multiple authors, an indication of the author who will receive correspondence; (c) any relevant citations to your previous work that have been omitted from the anonymous copies; and (d) acknowledgments, including the names of anyone who has provided comments on the manuscript. If the identified copy contains any unique references or is worded differently in any way, please mark this copy with "Contains author citations" at the top of the first page. 
No copies of submitted manuscripts can be returned.

\section{ELECTRONIC ACCESS TO THE APSR}

Back issues of the APSR are available in several electronic formats and through several vendors. Except for the last three years (as an annually "moving wall"), back issues of the APSR beginning with Volume 1, Number 1 (November 1906), are available on-line through JSTOR (http://www.jstor.org/). At present, JSTOR's complete journal collection is available only via institutional subscription, e.g., through many college and university libraries. For APSA members who do not have access to an institutional subscription to JSTOR, individual subscriptions to its APSR content are available. Please contact Member Services at APSA for further information, including annual subscription fees.

Individual members of the American Political Science Association can access recent issues of the APSR and $P S$ through the APSA website (www.apsanet.org) with their username and password. Individual nonmember access to the online edition will also be available, but only through institutions that hold either a print-plus-electronic subscription or an electronic-only subscription, provided the institution has registered and activated its online subscription.

Full text access to current issues of both the APSR and $P S$ is also available on-line by library subscription from a number of database vendors. Currently, these include University Microfilms Inc. (UMI) (via its CDROMs General Periodicals Online and Social Science Index and the on-line database ProQuest Direct), Online Computer Library Center (OCLC) (through its on-line database First Search as well as on CD-ROMs and magnetic tape), and the Information Access Company (IAC) (through its products Expanded Academic Index, InfoTrac, and several on-line services [see below]). Others may be added from time to time.

The APSR is also available on databases through six online services: Datastar (Datastar), Business Library (Dow Jones), Cognito (IAC), Encarta Online Library (IAC), IAC Business (Dialog), and Newsearch (Dialog).

The editorial office of the APSR is not involved in the subscription process to either JSTOR for back issues or the other vendors for current issues. Please contact APSA, your reference librarian, or the database vendor for further information about availability.

\section{BOOK REVIEWS}

The APSR no longer contains book reviews. As of 2003, book reviews have moved to Perspectives on Politics. All books for review should be sent directly to the Perspectives on Politics Book Review Editors, Susan Bickford and Greg McAvoy. The address is Susan Bickford and Gregory McAvoy, Perspectives on Politics Book Review Editors, Department of Political Science, University of North Carolina at Chapel Hill,
CB No. 3265, Chapel Hill, NC 27599-3265. E-mail: bookreviews@unc.edu.

If you are the author of a book you wish to be considered for review, please ask your publisher to send a copy to the Perspectives on Politics Book Review Editors per the mailing instructions above. If you are interested in reviewing books for Perspectives on Politics, please send your vita to the Book Review Editors; you should not ask to review a specific book.

\section{OTHER CORRESPONDENCE}

The American Political Science Association's address, telephone, and fax are 1527 New Hampshire Avenue, N.W., Washington, D.C. 20036, (202) 483-2512 (voice), and (202) 483-2657 (fax). E-mail: apsa@apsanet.org. Please direct correspondence as follows.

Information, including news and notes, for PS:

Dr. Robert J-P. Hauck, Editor, $P S$

E-mail: rhauck@apsanet.org

Circulation and subscription correspondence (domestic claims for nonreceipt of issues must be made within four months of the month of publication; overseas claims, within eight months):

Sean Twombly,

Director of Member Services

E-mail: membership@apsanet.org

Reprint permissions:

E-mail: Rights@cambridge.org

Advertising information and rates:

Advertising Coordinator, Cambridge University Press

E-mail: advertising@apsanet.org

\section{EXPEDITING REQUESTS FOR COPYING APSR AND PS ARTICLES FOR CLASS USE AND OTHER PURPOSES}

\section{Class Use}

The Comprehensive Publisher Photocopy Agreement between APSA and the Copyright Clearance Center (CCC) permits bookstores and copy centers to receive expedited clearance to copy articles from the $A P S R$ and PS in compliance with the Association's policies and applicable fees. The general fee for articles is 75 cents per copy. However, current Association policy levies no fee for the first 10 copies of a printed artide, whether in course packs or on reserve. Smaller classes that rely heavily on articles (i.e., upper-level undergraduate and graduate classes) can take advantage of this provision, and faculty ordering 10 or fewer course packs should bring it to the attention of course pack providers. APSA policy also permits free use of the electronic library reserve, with no limit on the number 
of students who can access the electronic reserve. Both large and small classes that rely on these articles can take advantage of this provision. The CCC's address, telephone, and fax are 222 Rosewood Drive, Danvers, MA 01923, (978) 750-8400 (voice), and (978) 750-4474 (fax). This agreement pertains only to the reproduction and distribution of APSA materials as hard copies (e.g., photocopies, microfilm, and microfiche).

The Association of American Publishers (AAP) has created a standardized form for college faculty to submit to a copy center or bookstore to request copyrighted material for course packs. The form is available through the CCC, which will handle copyright permissions.

APSA also has a separate agreement pertaining to CCC's Academic E-Reserve Service. This agreement allows electronic access for students and instructors of a designated class at a designated institution for a specified article or set of articles in electronic format. Access is by password for the duration of a class.

Please contact your librarian, the CCC, or the APSA Reprints Department for further information.

\section{APSR Authors}

If you are the author of an APSR article, you may use your article in course packs or other printed materials without payment of royalty fees and you may post it at personal or institutional web sites as long as the APSA copyright notice is included.

\section{Other Uses of APSA-Copyrighted Materials}

For any further copyright issues, please contact the APSA Reprints Department.

\section{INDEXING}

Articles appearing in the APSR before June 1953 were indexed in The Reader's Guide to Periodical Literature. Current issues are indexed in ABC Pol Sci; America, History and Life 1954-; Book Review Index; Current Contents: Social and Behavioral Sciences; EconLit; Energy Information Abstracts; Environmental Abstracts; Historical Abstracts; Index of Economic Articles; Information Service Bulletin; International Index; International Political Science Abstracts; the Journal of Economic Literature; Periodical Abstracts; Public Affairs; Public Affairs Information Service International Recently Published Articles; Reference Sources; Social Sciences and Humanities Index; Social Sciences Index; Social Work Research and Abstracts; and Writings on American History. Some of these sources may be available in electronic form through local public or educational libraries. Microfilm of the APSR, beginning with Volume 1 , and the index of the APSR through 1969 are available through University Microfilms Inc., 300 North Zeeb Road, Ann Arbor, MI 48106 (www.umi.com). The Cumulative Index to the American Political Science Review, Volumes 63 to 89: 1969-95, is available through the APSA. 